\title{
Qualitative Researchers, Heal (and Help) Thyself Too
}

\author{
Michael J. Zickar \\ Bowling Green State University
}

A persistent lament by qualitative organizational researchers is that qualitative research is not published, published enough, cited enough, or valued by industrial-organizational (I-O) psychologists. Pratt and Bonaccio (2016) present convincing data that there has been an increase in the visibility of qualitative studies throughout many organizational research journals, though some of the flagship journals in I-O psychology are less receptive. Also, they present a series of suggestions that largely entail ways that journal editors and nonqualitative researchers can adapt their attitudes and behaviors to help qualitative research have more of an impact. I agree with those suggestions and think that they should be pursued. On the other hand, I was disappointed that none of the suggestions presented by Pratt and Bonaccio offered things that qualitative researchers might do to make their research more impactful to I-O psychologists. For qualitative research to have a bigger impact in the organizational literature, qualitative researchers need to make changes as well. In this short commentary, I propose three things that qualitative researchers might do to improve their impact within the field of I-O psychology.

\section{Collaborate With Quantitative Researchers}

There is a tendency in our field (and all of academia in general) to specialize. Although notable exceptions exist, many of the I-O researchers advocating qualitative research conduct qualitative research almost exclusively. In many ways, they are methods focused as opposed to problem focused (the same criticism can certainly be applied to many quantitative researchers). Most research questions, however, do not break down neatly into problems that are best solved by either quantitative or qualitative methods but would

Michael J. Zickar, Department of Psychology, Bowling Green State University.

Correspondence concerning this article should be addressed to Michael J. Zickar, Department of Psychology, Bowling Green State University, Bowling Green, OH 43403. E-mail: mzickar@bgnet.bgsu.edu 
benefit from both. In fact, some of the earliest and best examples of I-O research do include both. Rexford Hersey (1932) was one of the first to explore workers' emotions and did so by interviewing workers along with their families and supervisors as well as administering standardized surveys on a frequent basis. Kornhauser (1965), in a study of the mental health of auto workers, interviewed workers at home, in addition to surveying them with anonymous surveys. These mixed-method studies provide converging data on topics, and their impact was probably larger given their diversity of methods (see Molina-Azorin, Bergh, Corley, \& Ketchen, 2014).

There is value in specialization, though there is also value in collaboration, and that collaboration goes both ways. Quantitative researchers would benefit from more serious attention to qualitative data. Often quantitative researchers pay lip service to qualitative data by providing open-ended items at the end of their surveys, though those results are often only used to reinforce a narrative created by quantitative results. We would all benefit if quantitative researchers used a more systematic approach to collecting and analyzing qualitative data. The same works for qualitative researchers. I was disappointed that such collaboration was not mentioned in by Pratt and Bonaccio.

\section{Focus on the Practical}

I-O psychology is inherently an applied field, surprisingly more so than organizational behavior and management. Only $28 \%$ of the respondents to the 2011 Society for Industrial and Organizational Psychology (SIOP) Member Survey reported being employed in academia; although I could not find comparable information for the Academy of Management, it is clear that the audience for top I-O psychology journals is more applied and practitioner focused (see SIOP, 2011). I believe that one of the reasons qualitative research has been less accepted in I-O journals is that qualitative researchers tend to ignore the practical side of our field. In general, qualitative researchers tend to avoid issues related to personnel selection and performance management, key issues within I-O psychology (for an exception see, Wilhelmy, Kleinmann, König, Melchers, \& Truxillo, 2015). Also, qualitative research often is impractical for applied researchers. Organizational ethnography can take 6 months or longer, making it difficult to do even for academic psychologists concerned with the tenure clock (see Zickar \& Carter, 2010). Other types of qualitative research can also take much longer than the pace required by organizations. Quantitative survey-based researchers have adapted to this quick pace demanded by business by coming up with online survey administrations and template-based reporting of results.

Qualitative researchers need to better adapt to the realities of the business cycle and to address applied problems of interest to I-O practitioners. In terms of the former, there are techniques such as virtual ethnography that 
allow researchers to engage in ethnography without having to be embedded within a particular organization for lengthy amounts of time (Hine, 2000). In terms of the latter, qualitative researchers should tackle practical problems that practicing I-O psychologists care about. Qualitative research that might be of interest to I-O practitioners include researching how different applicants perceive the selection and recruitment process and how individuals react to and interpret information communicated to them from their managers during performance review.

\section{Minimize Obfuscation!}

Academia is known for using confusing language, and each of our topic areas and methodologies have their own idiosyncratic terms and notations. One barrier to wider dissemination of qualitative methods is its reliance on confusing and complicated language and nomenclature. When I read many articles about qualitative methodology, I often think of the admonition attributed to Mark Twain: "Don't use a five-dollar word when a fifty cent word will do." People can use the same words and phrases, such as grounded theory, critical theory, or hermeneutics, and can be referring to completely different ideas and procedures. Suddaby (2006), in an editorial note, complained, "grounded theory' is often used as rhetorical sleight of hand by authors who are unfamiliar with qualitative research and who wish to avoid close description or illumination of their methods" (p. 633). Although Suddaby lays out a nice framework for grounded theory researchers to proceed, the same admonition would apply to nearly every technique of qualitative research. Another related barrier that Pratt himself acknowledged in a previous editorial is that "there is no accepted 'boilerplate' for writing up qualitative methods and determining quality" (Pratt, 2009, p. 856). This lack of standardization may be unavoidable in qualitative research, but leaders in qualitative methodologies can do a better job of providing and promoting standard templates. Pratt and Bonaccio lament how difficult it is to identify qualitative articles in traditional search engines. This may be a symptom of the lack of standardization of nomenclature by qualitative researchers.

Besides complicated and confusing nomenclature and unstandardized article templates is the problem of transparency. Bluhm, Harman, Lee, and Mitchell (2011) surveyed five organizational science journals and reviewed qualitative studies published from 2000 to 2010. One of their concerns was that $45 \%$ of the surveyed articles were not transparent about their methods and analyses; articles published in European journals were less transparent than articles in U.S. journals. This lack of transparency would not be tolerated in quantitative studies and should not be tolerated with qualitative research. 
The fact that there are sloppy qualitative researchers out there should not preclude high quality, rigorous qualitative research from any publication outlet. The prevalence of a general inattention to detail in the reporting of qualitative research methods, however, suggests that qualitative researchers still have work to do in terms of educating researchers and policing their own research area.

\section{Conclusions}

Pratt and Bonaccio's target article presents a compelling narrative that qualitative methods face discrimination within I-O psychology. I concur with them that the field of I-O psychology will greatly benefit from a more enthusiastic view of qualitative methodology. And the authors present useful ways that primarily quantitative researchers can be more supportive of qualitative research. I do however believe that there are still some significant reforms that can be made to help facilitate qualitative methodology's acceptance by I-O psychologists.

\section{References}

Bluhm, D. J., Harman, W., Lee, T. W., \& Mitchell, T. R. (2011). Qualitative research in management: A decade of progress. Journal of Management Studies, 48, 1866-1891.

Hersey, R. B. (1932). Workers' emotions in shop and home; A study of individual workers from the psychological and physiological standpoint. Philadelphia, PA: University of Pennsylvania Press.

Hine, C. (2000). Virtual ethnography. Thousand Oaks, CA: Sage.

Kornhauser, A. (1965). Mental health of the industrial worker: A Detroit study. New York, NY: Wiley. Molina-Azorin, J. F., Bergh, D., Corley, K., \& Ketchen, D. (2014). Feature topic: Mixed methods in the organizational sciences. Organizational Research Methods, 17, 111-112.

Pratt, M. G. (2009). From the editors: For the lack of a boilerplate: Tips on writing up (and reviewing) qualitative research. Academy of Management Journal, 52, 856-862.

Pratt, M. G., \& Bonaccio, S. (2016). Qualitative research in I-O psychology: Maps, myths, and moving forward. Industrial and Organizational Psychology: Perspectives on Science and Practice, 9(4), $693-715$.

Society for Industrial and Organizational Psychology. (2011). SIOP 2011 Membership Survey employment setting report. Retrieved from http://www.siop.org/userfiles/image/2011MemberSurvey/ Employment_Setting_Report.pdf

Suddaby, R. (2006). From the editors: What grounded theory is not. Academy of Management Journal, 49, 633-642.

Wilhelmy, A., Kleinmann, M., König, C. J., Melchers, K. G., \& Truxillo, D. M. (2015). How and why do interviewers try to make impressions on applicants? A qualitative study. Journal of Applied Psychology, 101, 313-332.

Zickar, M. J., \& Carter, N. T. (2010). Reconnecting with the spirit of workplace ethnography: A historical review. Organizational Research Methods, 13, 304-319. 